\title{
Cost minimization of locating construction machinery park with the use of simulation and optimization algorithms
}

\author{
Hubert Anysz ${ }^{1, *}$ and Jacek Zawistowski ${ }^{1}$ \\ ${ }^{1}$ Warsaw University of Technology, Faculty of Civil Engineering, Institute of Building Engineering, \\ Division of Production Engineering and Construction Management, ul. L.Kaczyńskiego 16, 00-637 \\ Warsaw, Poland
}

\begin{abstract}
Every construction project requires a plan of construction site, where storage areas, temporary roads, social containers, machinery parks etc. are shown. The location of the machinery park on a building site is very important. Cost is the most important factor for both, civil engineering structures and buildings in terms of the machinery movement. The everyday building machinery transport from the park to the working positions is time and cost consuming. Four possible solution of the location of temporary roads, necessary for such transport of the construction machinery, were discussed. Finding the optimum location of machinery park was presented, and case study calculations were made. Two dimension problem simulation has been applied, enhanced by heuristic algorithms to solve the discussed matter.
\end{abstract}

\section{The effectiveness of construction site}

The road construction market is very competitive and it has made the prices of construction resources similar for every contractor. The success of a contractor in these conditions, which is winning the contract, can be achieved mainly by optimization of technology and organizational skills. Decreasing the cost of transport, based on the well placed location of a road construction machinery park [5,7] is the example of such optimization. Shortening the total distance of transportation, limits some groups of the cost (see fig. 1):

- machinery cost,

- labour cost,

- overall construction site cost.

In other words, optimization is related to:

- shortening of non-productive time of machine operators,

- shortening of non-productive time of machinery operating,

- decreasing the length (and cost) of temporary roads construction.

\footnotetext{
* Corresponding author: h.anysz@il.pw.edu.pl
} 


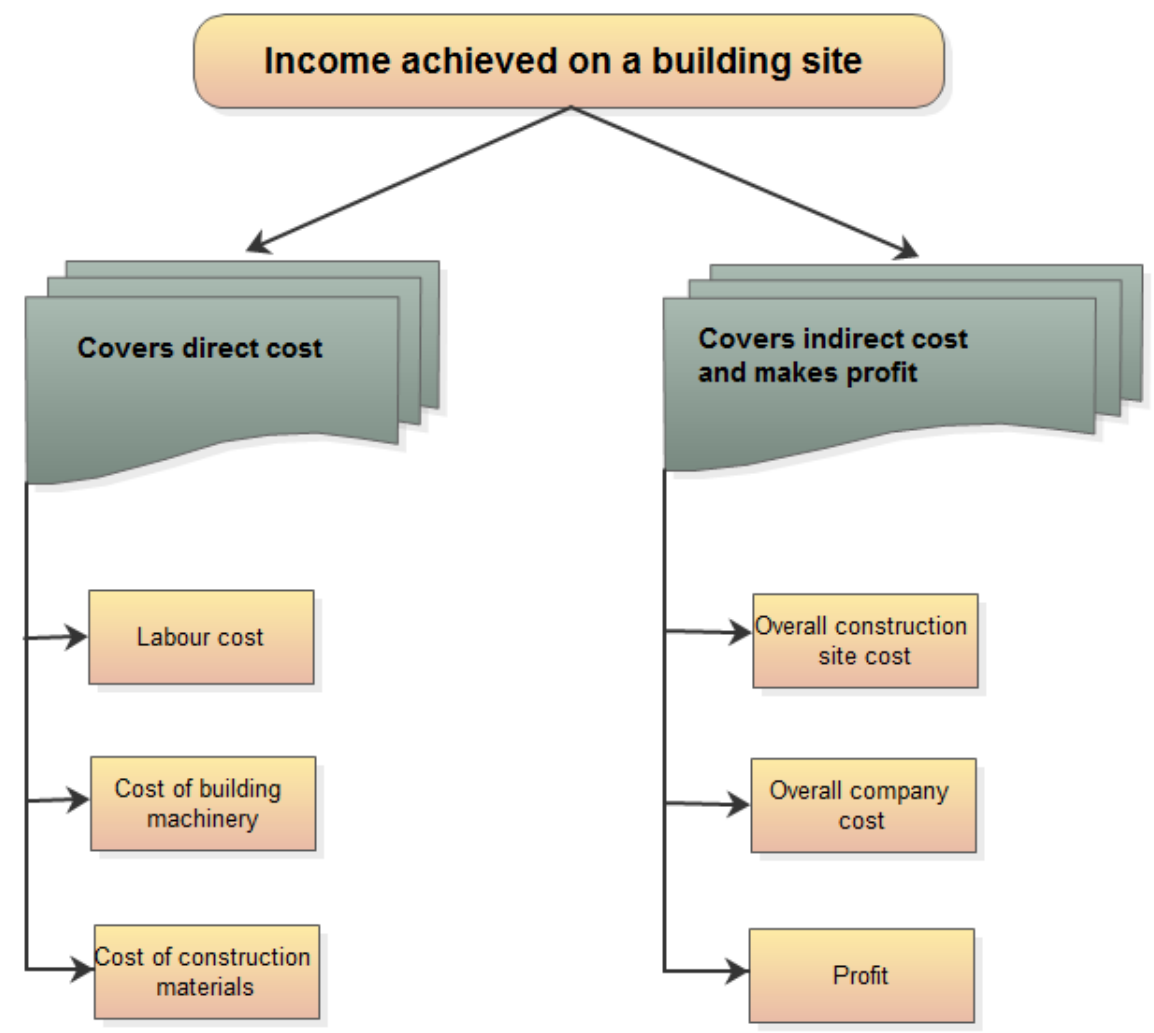

Fig. 1. Division of income achieved on construction site [3].

Savings achieved in aforementioned areas, can:

- lower a base of bid-price or,

- increase the profit achieved by a contractor $[2,12]$.

Searching for the optimum location of the machinery park is location type transportation problem [6].

\section{Temporary roads modelling}

\subsection{The assumption for the proposed models}

It was assumed that the trajectory (usually a curve) of the road under construction, can be approximated by a polygon. The centre of every section of the polygon should be connected with the construction machinery yard with the temporary road. The other assumptions are as follows:

- the sections of the polygon do not have to be equal,

- a given construction machine have to drive to the section where the works are carried out every day and it comes back to the park after work,

- there is a fixed number of days for each construction machine that they have to work on each section, 
- the volume of works do not have to be proportional to the length of the section of the polygon,

- the unit cost (per $\mathrm{km}$ ) of building a temporary road is independent from the load that is carried by a given section of the temporary road,

- there is only one machinery park location foreseen.

\subsection{The analysed models}

For the purpose of this article it was assumed the middle points of the four sections of the polygon will be labelled with letters $\mathrm{A}, \mathrm{B}, \mathrm{C}$ and $\mathrm{D}$. The location of the machinery park is labelled with Y.

MODEL I: the temporary road runs along the road being built; the machinery park is located on the temporary road (see fig. 2).

MODEL II: the temporary road connects every two middle points of adjacent sections of the polygon; the machinery park is located on the temporary road (see fig. 2).

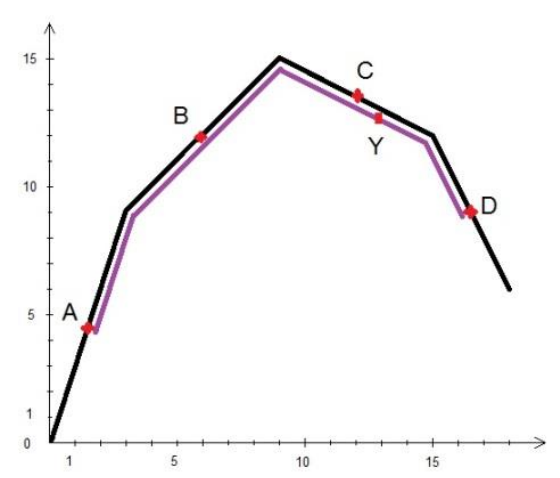

Fig. 2.

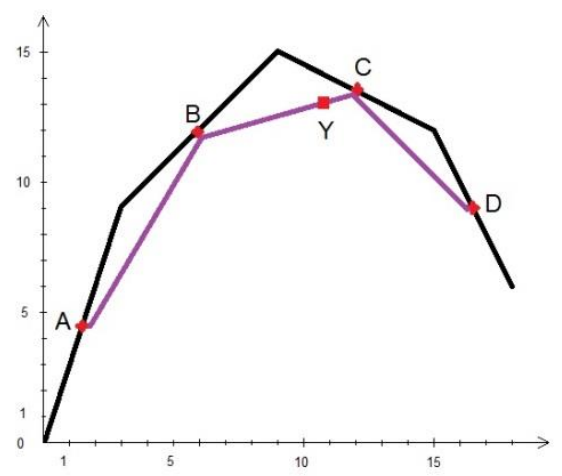

MODEL II.

MODEL III: the machinery park is located within the quadrilateral ABCD; there are separate temporary roads connecting the machinery park location $\mathrm{Y}$ with each middle point of the section of the polygon (see fig. 3).

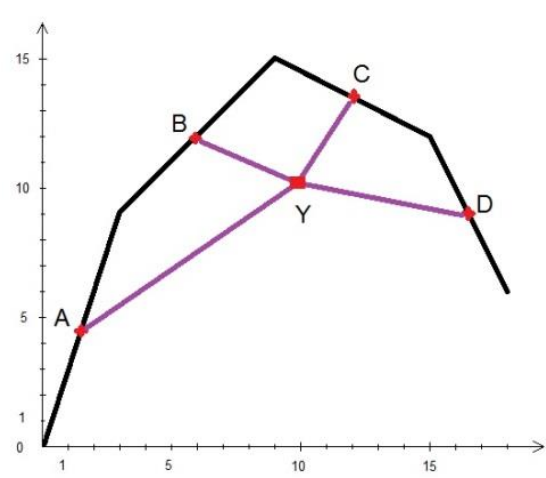

Fig. 3.

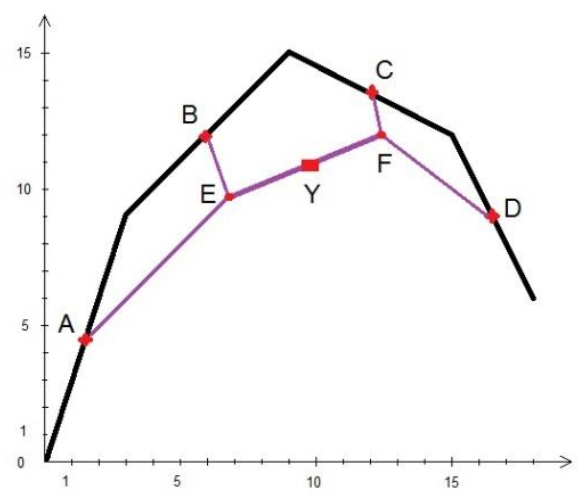

MODEL IV 
MODEL IV: the machinery park location Y is located within the quadrilateral ABCD; there are separate temporary roads connecting each middle point of the section of the polygon to the intermediate point ( $\mathrm{E}$ or $\mathrm{F}$ ) and then to the machinery park location $\mathrm{Y}$ (see fig. 3).

The exemplary shapes of temporary road system (shown in fig. 2 and 3) were created for the polygon, consisting of 4 parts, but proposed modelling is not limited by a number of sections of a polygon.

\subsection{The aim of the analysis}

In the Model I, II and III the coordinates of the machinery park $\left(x_{Y} ; y_{Y}\right)$ are searched to minimize the cost function $c$. The Model IV requires also finding the coordinates of points $\mathrm{E}$ and $\mathrm{F}$. The cost function can be defined as:

$$
c=\sum_{i=1}^{n}\left(l_{i} * c_{i}\right)+k * l
$$

where:

$l_{i} \quad$ the length of the temporary road from the machinery park to the center of $i$ section of the polygon (in $\mathrm{km}$ ),

$c_{i}$ the unit cost (per km) of transport of the set of machinery to the i section of the polygon, required number of times, twice a day,

$n$ number of the sections of the polygon (of the road under construction),

$k$ the unit cost (per $\mathrm{km}$ ) of building the temporary road,

$l \quad$ the total length of temporary roads necessary to be build.

It has to be noticed that equation (2)

$$
\sum_{i=1}^{n} l_{i}=l
$$

is valid only for the Model III.

In the formula (1) $l$ and $l_{i}$ depend on the shape of the polygon, the chosen model and the location of the machinery park. Additionally, they depend on the location of the intermediate points $\mathrm{E}$ and $\mathrm{F}$ in the Model IV. The unit cost of transport depends on much more parameters, such as:

- number of the machinery types necessary to apply on a given section of the polygon,

- the required number of working days necessary for each machine to spend on a given section,

- the average speed of each machine transport,

- fuel consumption of each machine,

- depreciation of each machine [1],

- the cost (per hour) for machine operators.

Since the Models I and II are - in fact - linear (the cost function depends only on the distance from the point A to the machinery park Y), it is relatively easy to find minimum of the cost and the respective location of the machinery park [4]. On the other hand, the Models III and IV cannot be solved in this manner. 


\section{The solution of the problem based on case study data}

\subsection{The input data}

The coordinates of the polygon sections (shown in fig. 2 and 3), their middle points and the lengths of the section are shown in tab. 1. The unit prices of the machinery transport and the unit price of constructing the temporary road, are shown in tab. 2 .

Table 1. Coordinates of the polygon sections

\begin{tabular}{|l|c|c|c|c|c|c|c|}
\hline \multirow{2}{*}{ Coordinates } & \multicolumn{2}{|c|}{ Start } & \multicolumn{2}{c|}{$\begin{array}{c}\text { Middle } \\
\text { point }\end{array}$} & \multicolumn{2}{c|}{ End } & \multirow{2}{*}{$\begin{array}{c}\text { length } \\
{[\mathbf{k m}]}\end{array}$} \\
\cline { 2 - 9 } & $\mathrm{x}$ & $\mathrm{y}$ & $\mathrm{x}$ & $\mathrm{y}$ & $\mathrm{x}$ & $\mathrm{y}$ & \\
\hline Section I with the middle point A & 0 & 0 & 1,5 & 4,5 & 3 & 9 & 9,487 \\
\hline Section II with the middle point B & 3 & 9 & 6 & 12 & 9 & 15 & 8,485 \\
\hline Section III with the middle point C & 9 & 15 & 12 & 13,5 & 15 & 12 & 6,708 \\
\hline Section IV with the middle point D & 15 & 12 & 16,5 & 9 & 18 & 6 & 6,708 \\
\hline
\end{tabular}

Table 2. The unit costs

\begin{tabular}{|l|c|}
\cline { 2 - 2 } \multicolumn{1}{c|}{} & The unit cost (per km) \\
\hline Transport from the machinery park to point A & 35 \\
\hline Transport from the machinery park to point B & 50 \\
\hline Transport from the machinery park to point C & 80 \\
\hline Transport from the machinery park to point D & 25 \\
\hline Building the temporary road & 150 \\
\hline
\end{tabular}

\subsection{Solutions for the Model I and the Model II}

The linear equations solved for the Model I and Model II (the method taken from [4]) has produced the optimum location of the machinery park in point $\mathrm{C}$. As the unit cost of the transport to the section with the middle point $\mathrm{C}$ is the highest, the minimum total cost is achieved when the distance from $\mathrm{Y}$ to $\mathrm{C}$ is equal to zero. It is worth noticing that changing the location of the machinery park does not change the total length of the temporary road for these two models. The temporary road is shorter in the Model II, so the result has confirmed expectations - the total cost was lower in that model.

\subsection{Solutions for the Model III and the Model IV}

Finding the location of the machinery park - in the Model III - with the use of simulation, has required assuming two variables being simulated - the coordinates of the point Y. The result found show that the total cost for the Model III is higher than achieved in the Model I and the Model II. For the Model IV the Authors assumed, that the calculation model will consist of six decision variables, related to coordinates $\mathrm{x}$ and $\mathrm{y}$ of the central point $\mathrm{Y}$ and intermediate points $\mathrm{E}$ and $\mathrm{F}$. Additionally, six variables were defined and described by the 
uniform probability distributions, for the Monte Carlo simulation of possible locations of all mentioned above points. The objective function was defined to minimize the final value of the cost of transportation and construction of temporary roads.

The process of simulation and optimization was aided by the use of computer software - Oracle Crystal Ball. The simulation process is focused on selecting a value for each variable described by a probability distribution and entering those values into the spreadsheet. Then a Monte Carlo simulation is run on the spreadsheet, results recorded and the process repeated usually several thousand times or even more. Authors used 10000 simulation iterations for the purpose of receiving the assumed level of confidence for every optimization pass [14]. It is possible to manually perform this analysis but with the increased number of decision variables, the number of possible variable combinations becomes too high to do it manually. To speed up the process of calculation, which depending on the complexity of a model can last from several minutes to hours, an optimization tool was selected to incorporate highly effective methods of searching and finding the optimal solution [11]. For this purpose, the OptQuest optimization tool was chosen. At more advanced level, OptQuest does a much more efficient calculations at finding optimal solutions than it would be possible with manual calculations or even simulation methods. OptQuest offers a possibility to surpass the limitations of genetic algorithm optimizers because it uses multiple, complimentary search methodologies, including advanced tabu search and scatter search, to help find the best global solutions $[13,15]$. In addition, the optimization algorithm applies some elements of adaptive and neural network technologies to help it learn from past optimizations in order to achieve better results in less time [10]. The authors assumed that the optimization process should calculate the model for 100000 iterations. The optimization achieved the best, optimal result very quickly, after several minutes of calculations and approximately 25000 iterations, giving the best optimal result of 4184,18 for a given set of coordinates. The results listed in the Table 3 show, that the coordinates found through simulation and optimization for points E, F and Y are coherent with results found with Model II, and give the best possible solution for the given construction site.

\subsection{Results achieved}

The results of the optimization, i.e. the cost minimization, in a form of the machinery park coordinates are shown in tab. 3 for all four models.

Table 3. Results achieved

\begin{tabular}{|c|c|c|c|c|c|c|}
\hline \multicolumn{2}{|r|}{ Temporary road variant } & \multicolumn{2}{|c|}{ The park coordinates } & \multirow{2}{*}{$\begin{array}{c}\text { Cost of } \\
\text { self- } \\
\text { transport }\end{array}$} & \multirow{2}{*}{$\begin{array}{c}\text { Cost of } \\
\text { temporary } \\
\text { road } \\
\end{array}$} & \multirow{2}{*}{ Total cost } \\
\hline No. & Description & $\mathbf{x}$ & $\mathbf{y}$ & & & \\
\hline I & Along the constructed road & 12,0 & 13,5 & 1127,94 & 3493,65 & 4621,59 \\
\hline II & The polygon $\mathrm{ABCD}$ & 12,0 & 13,5 & 990,92 & 3194,26 & 4185,18 \\
\hline III & The star in the center in $Y$ & 9,65 & 11,47 & 990,43 & 3719,70 & 4710,13 \\
\hline IV & $\begin{array}{l}\text { The star in the center in Y } \\
\text { with intermediate points in: } \\
\text { E } \\
\text { and F }\end{array}$ & $\begin{array}{c}12,0 \\
6,0 \\
12,0 \\
\end{array}$ & $\begin{array}{l}13,5 \\
12,0 \\
13,5\end{array}$ & 990,92 & 3194,26 & 4185,18 \\
\hline
\end{tabular}

The results of calculations show that in the analysed case, the use of the simulation (enhanced by heuristics) - the Model IV - has produced the same result as the exact method in the Model II. The point $\mathrm{E}$ was shifted to the point $\mathrm{B}$ and the points $\mathrm{Y}$ and $\mathrm{F}$ were shifted to the point $\mathrm{C}$ (see fig. 2 - Model II and fig. 3 Model IV). The more complicated 
shape of the temporary road assumed in Model IV (as starting point of searching the minimum cost) has been transferred to the more simple shape (assumed in the Model II). The location of the machinery park found in these two models is exactly the same, so the total costs are. The minimum cost found in the Model I was 10,4 \% higher and 12,5\% higher in the Model III, than the minimum one produced in the Model II and IV.

\section{Conclusions}

The analysed case of finding the optimum location of construction machinery park has led to the cost minimization. The sum of transportation cost and the cost of building the temporary road (necessary for the daily transport of the machinery) has reached its minimum value. The similarity of results achieved in Model IV (where the simulation and heuristics have been applied) and in Model II (the exact solution) allow saying that for the assumed shape of temporary roads, the global minimum of the cost has been found. Nevertheless, this similarity cannot be treated as a rule. Many factors can influence the achieved result. The relation of the unit transport cost to the unit cost of building the temporary road, the length of the constructed road and its shape, the number of sections of the road being built, are the examples of parameters able to change the model, where the optimum cost will be found. It is recommended to check every time all four proposed models to find the location of the machinery park. The savings (in the analysed case) are higher than $10 \%$ of the total cost. The next positive effect of finding the optimum location of the machinery park is raising the daily effectiveness of the set of construction machinery. Since a day has a limited number of hours, shortening the time of daily transport allows for longer utilization of the machinery at their workplaces. The paper is an example of the successful computer aided decision supporting system [8] which allows for savings and easier controlling the schedule of a construction site [9].

\section{References}

1. Polish Accounting Law, Ustawa z dnia 29 września 1994 r, o rachunkowości (Dz.U. $1994 \mathrm{Nr} 121$ poz 591) with subsequent changes

2. M.M. Ahmed, N. Sultana, A.R. Khan, Md.S. Uddin, An Innovative Approach to Obtain an Initial Basic Feasible Solution for the Transportation Problems, Journal of Physical Sciences, Vol. 22, 2017, pp. 23-42 (2017)

3. H. Anysz, The profit as in-company evaluation of the construction site effectiveness, MATEC Web of Conferences 117:00009, DOI: $10.1051 /$ matecconf/201711700009 (2017)

4. H. Anysz, The cost minimizing solution of the transportation problem for the location of the building machinery yard along the road under construction, Scientific Review Engineering and Environmental Sciences 27(1(79))

DOI: 10.22630/PNIKS.2018.27.1.3 (2018)

5. S. Biruk, K.M. Jaworski, Z. Tokarski, Podstawy organizacji robót drogowych, Warszawa, Wydawnictwo Naukowe PWN (2009)

6. O. Diaz-Parra, J.A. Ruiz-Vanoye, B.B.Loranca, A. Fuentes-Penna, R.A. BarreraCámara R.A., A Survey of Transportation Problems, Journal of Applied Mathematics, Vol. 2014, DOI: 10.1155/2014/848129 (2014)

7. K.M. Jaworski, Metodologia projektowania realizacji budowy, Warszawa, Wydawnictwo Naukowe PWN (2009) 
8. M.V. Książek, P.O. Nowak, S. Kivrak, J.H. Rosłon, L. Ustinovichius, Computer-aided decision-making in construction project development. Journal of civil engineering and management, 21(2), 248-259 (2015)

9. J. Rosłon, The multi-mode resource constrained project scheduling problem in construction. State of the art review and research challenges. Technical Transactions, Volume 5, pp. 67-74 (2017)

10. J.Rosłon, Porównanie algorytmów genetycznego i przeszukiwania tabu wykorzystanych do szeregowania zadan w budownictwie (Comparison of the genetic and tabu search algorithms for the task execution in construction projects ). Materiały Budowlane, 2016, DOI: 10.15199/33.2016.06.18

11. J. Rosłon, J. Zawistowski, Construction projects' indicators improvement using selected metaheuristic algorithms, Procedia Engineering, 2016, 153, 595-598,

12. I. Rybka, E. Bondar-Nowakowska, K. Pawluk, M. Połoński, Risk of contractors' claims on the example of road works. IOP Conference Series: Materials Science and Engineering 2017, Vol. 245, art. 072009, s. 1-9, DOI: 10.1088/1757899X/245/7/072009 (2017)

13. https://docs.oracle.com/cd/E57185_01/CBOUG/ch03.html - OptQuest Guidelines for Setting up and Optimizing a Model

14. https://www.oracle.com/applications/crystalball/index.html

15. https://www.oracle.com/applications/crystalball/decision-optimizer/index.html 